\title{
Paleobathymetry of submarine lavas in the Samail and Troodos ophiolites: insights from volatiles in glasses and implications for hydrothermal systems
}

\author{
THOMAS M BELGRANO ${ }^{1,2}$, PETER M TOLLAN ${ }^{3}$, FELIX \\ MARXER $^{3}$ AND LARRYN W. DIAMOND ${ }^{4}$ \\ ${ }^{1}$ School of Ocean and Earth Science, National Oceanography \\ Centre Southampton, University of Southampton \\ ${ }^{2}$ School of Ocean and Earth Science, University of Southampton \\ ${ }^{3}$ Institute of Geochemistry and Petrology, ETH Zurich \\ ${ }^{4}$ Institute of Geological Sciences, University of Bern \\ Presenting Author: T.Belgrano@soton.ac.uk
}

\begin{abstract}
Hydrostatic pressure exerted by the ocean water column fundamentally influences hydrothermal processes in ocean ridge settings and is therefore an important parameter to know when investigating these systems. Currently, there are few reliable methods for reconstructing past ocean depths for ophiolites. Here, we develop and test an empirically calibrated statistical approach for determining paleodepths of eruption from the concentrations of $\mathrm{H}_{2} \mathrm{O}$ and $\mathrm{CO}_{2}$ dissolved in volcanic glasses, utilizing the well-defined pressure-dependent solubility of these volatiles in silicate melts. We then apply this approach to the archetypal Samail and Troodos ophiolites, proposing that the Samail lavas erupted at ocean depths somewhere between 3.2 and $4.0 \mathrm{~km}$, and the Troodos lavas somewhere between 3.6 and $4.9 \mathrm{~km}$. These depths are $1-2 \mathrm{~km}$ deeper than those assumed in most previous studies of hydrothermal activity in the two ophiolites and imply high hydrostatic pressures within the underlying oceanic crust. Such pressures would have allowed hydrothermal fluids at the base of the sheeted dykes to stay in a single phase above temperatures of $500^{\circ} \mathrm{C}$. Whether convecting hydrothermal fluids actually attained such temperatures depends on the validity of the hypothesis that fluids begin their ascent from the point of peak fluid fluxibility, the temperature of which increases with hydrostatic pressure [1]. If true, the high hydrostatic pressures exerted on the ophiolite hydrothermal systems could partly explain their greater overall degrees of hydrothermal alteration and larger seafloor sulfide deposits than for structurally similar mid-ocean or back-arc oceanic crust.
\end{abstract}

[1] Jupp \& Schultz (2000), Nature 403, 6772, 880-883. 